\title{
Child tooth decay figures rise again
}

The number of children aged 5 to 9 who were admitted to hospital due to tooth decay has risen for the second consecutive year, according to official figures. ${ }^{1}$

Statistics from NHS Digital published on 20 September 2018 showed that the number of hospital admissions for tooth decay for children aged 5-9 rose slightly from 25,923 in 2016-2017 to 26,111 in 2017-2018.

The figures reached a five-year high in 2014-15 when they grew to 26,708 and then dropped slightly to 25,875 in $2015-2016$ before rising again for the next two years.

Tooth decay remains the main reason that children aged 5-9 are admitted to hospital and last year the youngest who needed this treatment were two children aged less than a year old.

However, hospital admissions for tooth decay in other child age groups have fallen. The data show that for 1-4-year-olds, the number dropped from 8,281 in 2016-2017 to 7,666 in 2017-2018.

Similarly, among 10-14-year-olds, admissions fell from 7,303 in 2016-2017 to 7,060 in 2017-2018.

Overall, 44,047 children aged between 0 and 19 were admitted to hospital because of tooth decay in 2016-2017, down from 45,224 the previous year. The figures also show that more than double the number of 5-9-year-olds were admitted to hospital for tooth decay $(26,111)$ than acute tonsillitis $(12,143)$ in $2017-2018$, followed by 10,390 admitted for a viral infection of unspecified site, 9,724 for asthma and 8,910 for abdominal and pelvic pain.

Responding to the figures, Professor Michael Escudier, Dean of the Faculty of Dental Surgery, said: 'It is disappointing that we haven't seen the same improvement in the number of children aged 5 to 9 being admitted to hospital for dental decay as we have for other age groups.

'These children will likely be having teeth removed in hospital under general anaesthetic - something that should never be taken lightly. When you consider that tooth decay is $90 \%$ preventable and NHS dental treatment is free for all under 18 s, it is disgraceful that so many children in their early years of school are suffering time away from class to have teeth removed.

'Parents and carers must ensure children visit the dentist regularly, eat less sugar and brush twice a day with a fluoride toothpaste. Supervised tooth brushing sessions in nurseries and primary schools are an excellent way to instil good oral health habits at an early age, and there should be support for these programmes in the NHS long-term plan.'

Dr Sandra White, Dental Lead for Public Health England, said: 'While dental health in England is improving for 5-year-olds, almost a quarter of 5-year-olds are still suffering from preventable tooth decay and children in our most deprived communities continue to be hit the hardest.

'To reduce these inequalities, targeted interventions such as supervised tooth brushing with fluoride toothpaste should be put in place alongside reducing sugar consumption initiatives.'

1. NHS Digital. Hospital Admitted Patient Care Activity, 2017-18 (20 September 2018). Available at https://digital.nhs.uk/data-and-information/publications/statistical/hospital-admitted-patient-care-activity/2017-18. (accessed on 2 October 2018). 